\title{
Sense of Community among Nurses: Results of a Study
}

\author{
Liz Mary Ditzel ${ }^{1}$ \\ ${ }^{1}$ School of Nursing, Otago Polytechnic, Dunedin, New Zealand \\ Correspondence: Liz Mary Ditzel, School of Nursing, Otago Polytechnic, Dunedin, New Zealand.
}

Received: July 11, 2017

Accepted: August 4, 2017

Online Published: October 10, 2017

doi:10.20849/ijsn.v2i2.191

URL: https://doi.org/10.20849/ijsn.v2i2.191

\begin{abstract}
Sense of community has four elements: 1) membership, 2) influence, 3) integration and fulfillment of needs, 4) shared emotional connection. It is a term often used in relation to a geographic location, as in a neighbourhood, town or region. However, the concept encompasses much more than location and is often extended to include the work environment and relationships people build with co-workers. Scant attention has been paid to developing and testing the construct among nursing communities. This study explores how a theoretical conceptualisation of sense of community applies to nurses; describes the development of the Nurse Sense of Community Index (NSCI), and reports the results of a survey $(\mathrm{N}=672)$ of New Zealand nurses.

Key findings relate to high membership and low influence subscale scores, low levels of sense of community among the youngest nurses, and high levels among those working in speciality areas (i.e., small, close-knit workplaces). In addressing these issues it is recommended that early-career nurses be placed in smaller sized workplaces or teams and that preceptor and mentor programmes be used to enhance the development of sense of community among mid-career nurses. Significantly, findings demonstrate the presence of a sense of community among nurses and provide evidence that the NSCI reliably measures the construct.
\end{abstract}

Keywords: sense of community, nurse sense of community index, nurses, workplace, New Zealand

\section{Introduction}

Recent academic publications, newspaper and media headlines tell readers worldwide that healthcare professionals will continue to be confronted daily with more difficulties: worsening recruitment and retention, lack of staff and heavy workload (Blockley, 2017; Buck, 2017). We also know that all members of society experience the need for community in that our lives become more meaningful through a sense of belonging, of being connected to and supported by others. These connections are what make our lives significant. Community in human life is critical because it ties individuals together in ways that foster shared values and beliefs: and that work communities can transform organisational members from a collection of singular individuals to a collective 'we' giving them a unique sense of belonging. For nurses, establishing supportive relationships with co-workers and feeling a sense of community at work are closely associated with higher job satisfaction, lower levels of job stress and reduced likelihood of burnout (Ditzel, 2008; 2009), especially for new graduates who are often the most vulnerable to stress during challenging times (Sherman, 2013). Having a sense of community is crucial for today's nurses because staff may often spend as much time with one another at work as they do with family members (Thueson, 2002) and for some, work may be their only source of community, so a sense of belonging and ownership matters even more (Seckman, 2014).

\subsection{Sense of Community}

Sarason (1974) first conceptualized a psychological sense of community to describe the phenomena that one belongs to and is an integral part of a larger collectivity. Using the concept to represent the strength of bonding among community members, he argued that it was important for personal and collective well-being and associated the absence of a psychological sense of community with loneliness, alienation, psychological distress, and a feeling of powerlessness in society. Further developing the concept, McMillan and Chavis (1986) defined a sense of community as "a feeling that members have of belonging, a feeling that members matter to one another and to the group, and a shared faith that members' needs will be met through their commitment to be together" (p. 9). The authors proposed that a sense of community has four elements: 1) membership, feelings of emotional security, belonging, and identification; 2) influence, by which the community influences the individual and the individual influences the community, in turn; 3) integration and fulfillment of needs, physical and psychological 
needs met, thereby reinforcing one's commitment to the group; and 4) shared emotional connection, positive affect and shared history related to community membership (McMillan \& Chavis, 1986).

The concept of sense of community has been investigated in a variety of settings including workplaces (Klein \& D’Aunno, 1986; Pretty \& McCarthy, 1991, Price, 1985); schools (Royal \& Rossi, 1996; Spann, 2000) and online learning communities (Seckman, 2014). Findings indicate that having a strong sense of community plays an important role in protecting individuals from negative outcomes such as poor physical and mental health (Pretty \& McCarthy, 1991), improves morale (Burroughs \& Eby, 1998), increases job satisfaction and lowers absenteeism in the case of teachers (Royal \& Rossi, 1996). In healthcare, having a strong sense of community yields benefits such as greater job satisfaction, improved staff retention and morale, better coping behaviours (Buck, 2017).

\subsection{Research Purpose and Questions}

Apart from Biester's (1994) doctoral research on creating professional nursing work environments and a recent study of sense of community among nursing students (Foli, Karagory, Gibson, et al. 2013), scant attention has been paid to developing and testing the construct among nursing communities. This gap in the literature provided the opportunity and motivation for this research. This study addresses the following questions:

- How does a theoretical conceptualisation of a sense of community apply to nurses?

- What is the level of sense of community among nurses?

The implications of the study's findings for the nursing profession and the relevance of place of work are discussed at the conclusion of the paper.

\subsection{How Does a Theoretical Conceptualisation of a Sense of Community Apply to Nurses?}

McMillan and Chavis' (1986) conceptualisation of sense of community deeply resonates with the writer's personal experience of feeling of belonging to a community of nurses. This experience and relevant literature is used to discuss how the four elements might operate for nurses.

\subsubsection{Membership}

Membership, the first element, has five attributes; boundaries, emotional safety, a sense of belonging and identification, personal investment, and a common symbol system (McMillan \& Chavis, 1986). The first attribute, boundaries specify who is and who is not considered as part of the community or group. They are fixed formally with explicit markers of membership, and joining and leaving rituals. These barriers protect against threats to their intimate social connections, separating 'us' from 'them' thereby allaying anxiety by delimiting who can be trusted. In applying this, nurses begin their education as strangers but end up as members of a professional community with a fixed formal boundary. Becoming a registered nurse is the professional marker of membership and labels such as 'student nurse' and 'registered nurse', 'theatre nurse', etc., specify who is (and who is not) part of the various subgroups that exist within this vocational community.

A sense of belonging and identification, the second membership attribute involves the feeling, belief, and expectation that one fits in the group and has a place there, experiences a feeling of acceptance by the group and a willingness to sacrifice for the group. Members identify by believing that 'this is my group', and 'I am part of this group'. For nurses, group members develop a shared experience of nursing practice that conforms to both the formal rules of the vocational community and the informal rules of the various subgroups within the community. Personal investment, the third attribute is an important contributor as to how an individual feels about group membership and his or her community and is aligned with the fourth attribute, emotional safety which forms part of the broader notion of security. For nurses, emotional safety develops as individuals spend many hours together learning to become a nurse. Having a feeling of emotional safety relates to personal investment of time and self that in turn fosters intimacy and emotional safety as membership bonds grow. This plays a large role in developing an emotional connection (the fourth element).

The fifth membership attribute, a common symbol system serves several important functions in creating and maintaining a sense of community, one of which is to maintain group boundaries. Groups may use symbols such as the special conventions (e.g. rites of passage, language, dress, etc.) as boundaries to create intentionally social distance between members and non-members. For nurses, the most visible symbol of membership - wearing a nurses' registration badge, name badge or uniform - formally identifies a nurse as a community member. Other outward symbols include language, such as jargon like the word 'drip' meaning an intravenous infusion line, or 'red light' meaning there is an emergency. 


\subsubsection{Influence}

Influence is "a sense of mattering, of making a difference to a group and of the group mattering to its members" (McMillan \& Chavis, 1986, p. 9) and it works in various ways. Firstly, members are more attracted to a community in which they feel they are influential. Secondly, that community's influence on its members is an indicator of the strength of the bond between an individual and the community. Thirdly, the pressure for conformity comes from the needs of the individuals and the community for consensual validation (the need to know that the things the individuals feel, see, and understand are experienced in the same way by others), and, fourthly, that the influence of a member on the community and the influence of the community operate on a member concurrently. In a strong community, McMillan and Chavis (1986) argued that influence operates bi-directionally: members of a group are able to influence their community and the community in turn exerts control over the behaviour of its members. Nurses need to feel that they are contributing to their work unit to have influence. Examples include involvement and participation in work group decision making and contributing to ongoing education.

\subsubsection{Integration and Fulfilment of Needs}

The third element, integration and fulfilment of needs, is the "feeling that members' needs will be met by the resources received through their membership in the group" (McMillan \& Chavis, 1986, p. 9). This includes that which is desired and valued by the community. The following extract explains how a student nurse felt when integrated into a group of registered nurses working on a clinical ward.

Well they showed me the ropes. Expanded a little on what I learned in theory, well a large amount of what I learned in theory, let me get my hands on, as soon as they noticed I was gaining confidence, they let me build up my own confidence and work away on my own pretty quickly (Cope, Cuthbertson, \& Stoddart, 2000, p. 854).

An example of a formal group established to integrate and fulfil palliative care nurses' needs is the Nursing Leadership Academy in End-of-Life Care (known as the Academy) (Spencer, Rushton, Rumizen et al., 2003). The Academy was set up to bring about change because nurses working in the end-of-life field had recognised that improvements in medicine have led to longer and better lives, and that the art of caring for the person became secondary. The desire to change came from their desire to provide the best possible level of care, transmitted through a shared emotional connection and sense of belonging to a community of palliative care nurses (Spencer, et al., 2003).

\subsubsection{Shared Emotional Connection}

The final element is a shared emotional connection or the belief that members share history, common places, similar experiences and time together that is based upon a history of interaction. It is "the definitive element for true community" (McMillan \& Chavis, 1986, p. 14) and has been described as the feeling one gets when talking with other nurses or the look one sees in nurses faces when they talk about a 'favourite patient' or a 'moving experience' (Benton \& Mitchell, 2004). The strength of emotional connection increases with the greater number and quality of interactions and conflicts that are resolved. To illustrate this, a nurse who has cared for a person who is only hours' away from death knows (based on experience and stories that others have told) that hearing is one of the last senses to function. Experienced carers develop a confidence that engages them in a shared repertoire of talking 'out loud' to the person, even though that person apparently cannot hear nor respond (Kübler-Ross, 1969). Nurses holding normal everyday conversations with each other also direct the conversation to the patient rather than being silent in their presence. To the family member, or even a novice nurse, this practice of having a normal conversation with a dying patient may appear as nonchalant or even disrespectful. To the nurses engaged in caring and, in my own experience, it is a congruent shared practice of nursing. Nurses who are community members experience a sense of belonging founded upon this shared knowledge and emotional connection about how to care for a dying person. A nurse who did not feel this sense of community, may feel ill at ease and may even experience emotional distress in this same situation.

\section{Method}

\subsection{The Sense of Community Index}

The most widely used measure of sense of community, the Sense of Community Index (SCI) is a 12-item true or false questionnaire developed from the responses of 12,000 adults in a neighbourhood participation project (Chavis, 1986; Chavis, Hogge, McMillan et al., 1986). SCI items are rated 'true' $=1$ or 'false' $=0$ and are grouped together into four subscales based on their conceptual relevance to each of the four theoretical dimensions as follows: fulfilment of needs (items 1,2,3), membership (items 4, 5, 6), influence (items 7, 8,9), and shared emotional connection (items $10,11,12$ ) (Note 1). An overall sense of community score is a total of all items (range 
0 to 12) (Note 2). The SCI is commonly used in the neighbourhood context (Davidson \& Cotter, 1986) but it has also been adapted (e.g., 'block' changed to 'your workplace', 'neighbours' to 'workmates') and in studies dealing with other geographic and relational communities including workplaces (Pretty et al., 1992; Price, 1985), educational settings (e.g. Royal \& Rossi, 1996), urban communities (Chavis \& Wandersman, 1990; Thueson, 2000) and professional nursing environments (Biester, 1994). Construct validity of the SCI has been established by several qualitative studies (e.g. Brodsky 1996; Sonn \& Fisher, 1996; Plas \& Lewis, 1996).

\subsection{The Nurse Sense of Community Index}

For the purposes of this study, the Nurse Sense of Community Index (NSCI) was developed by making three modifications to the original version of the SCI.

1. The referent 'block' was changed to 'hospital/organisation' and the word 'neighbours' was altered to 'colleagues'.

2. A five-point Likert scale was adopted (Burroughs \& Eby, 1998; Laughner, 2004) for the 12 items (1=not at all, through to $5=$ all the time) to produce a score range of 12 to 60 .

3. Statements expressed in the negative condition (were altered to the positive condition to ensure that "all items were scored so high scores reflect high sense of community" (Chipuer \& Pretty, 1999, p. 649).

\subsection{Sampling Procedures}

The New Zealand nurses' survey used a self-reported questionnaire that was first administered as a pilot study to in a convenience sample of 49 nurses attending a hospital-based preceptor study day. Results showed an acceptably high reliability alpha co-efficient for the NSCI scale (0.82). Following ethical approval from the researcher's university, and with permission from the New Zealand Nurses' Organisation (NZNO) the questionnaire was administered nationally as a postal survey. Standard demographic information such as respondents' age, gender, family situation, and marital status was requested. To guarantee anonymity a tick-box method was used to complete the survey. Professional and employment related data was collected in the same way. Data were coded and entered into the SPSS 13.0 programme. Mean and standard deviation were computed to analyse the quantitative data.

\section{Results}

\subsection{Sample}

Respondents were 672 nurses ( 25 males and 627 females) who voluntarily completed a survey that was distributed in KaiTiaki, the monthly journal of the NZNO. Three quarters (74\%) were married or living with a partner and a third was aged between 41 and 50 years: the median age group. Slightly over half had independent children living with them. The majority (64\%) worked in public hospitals: were full-time employees and, collectively, $80 \%$ held hospital clinical nursing positions (in medical, surgical, children's wards, etc.). Job tenure data indicated a pattern of stability and longevity of tenure of many respondents (18.3\% up to one year, $26.8 \%$ for three to five years, $17.3 \%$ for five to ten years, and $23.1 \%$ for ten years or more).

\subsection{NSCI Scale Data}

Data were first analysed to evaluate the four-element structure of the NSCI scale. Results are shown in Table 1. 
Table 1. NSCI scale data

\begin{tabular}{|c|c|c|c|}
\hline Items & Mean & SD & $\alpha$ \\
\hline 1) I think this hospital/organisation is a good place for me to work. & 3.78 & 0.97 & \\
\hline 2) People in this hospital/organisation share the same values. & 3.37 & 1.00 & \\
\hline 3) My colleagues and I want the same things from our work. & 3.69 & 0.92 & \\
\hline 4) I can recognise most of the people who work in this hospital/organisation. & 3.48 & 1.31 & \\
\hline 5) I feel at home in this hospital/organisation. & 3.80 & 0.95 & \\
\hline 6) Most of the people who work in this hospital/organisation know me. & 4.19 & 0.91 & \\
\hline $\begin{array}{l}\text { 7) I care about what the people who work in this hospital/organisation think of } \\
\text { my actions. }\end{array}$ & 4.24 & 0.75 & \\
\hline 8) I have influence over what this hospital/organisation is like to work in. & 2.08 & 0.81 & \\
\hline $\begin{array}{l}\text { 9) If there is a problem in this hospital/organisation people who work here can } \\
\text { get it solved. }\end{array}$ & 3.16 & 1.06 & \\
\hline 10) It is very important for me to work in this particular hospital/organisation. & 3.32 & 1.08 & \\
\hline 11) People in this hospital/organisation generally get along with each other. & 3.59 & 0.87 & \\
\hline 12) I expect to work in this hospital/organisation for a very long time. & 3.43 & 0.10 & \\
\hline \multicolumn{4}{|l|}{ Element subscales } \\
\hline Membership (items 4, 5 \& 6) & 11.47 & 2.57 & 0.70 \\
\hline Influence (items 7, 8 \& 9) & 9.47 & 1.64 & 0.18 \\
\hline Integration and fulfilment of needs (items $1,2 \& 3$ ) & 10.84 & 2.33 & 0.73 \\
\hline Shared emotional connection (items $10,11 \& 12$ ) & 10.34 & 2.42 & 0.70 \\
\hline \multicolumn{4}{|l|}{ Overall scale } \\
\hline 12 items (score range $12-60$ ) & 42.12 & 7.15 & 0.84 \\
\hline
\end{tabular}

Table 1 shows the mean and standard deviations for each item on the NSCI and for the four sense of community element subscales. Data reports a very high score (11.47) for membership, a low score $(\mathrm{M}=9.47, \mathrm{SD}=1.64)$ and an unacceptably low Cronbach's alpha co-efficient of 0.18 for the Influence subscale. Results of a principal axis factor test for the NSCI items revealed a three-factor solution for the NSCI scale where factor 1 accounted for $51 \%$ of the variance and comprised eight items. Further testing of the intercorrelations and factor loadings revealed a common sense of community factor since the two subscales loaded onto a single factor. These results support the practice of using the overall SCI score in data analyses. Table 2 contains a summary respondents' NSCI score data. 
Table 2. NSCI scores among variables

\begin{tabular}{|c|c|c|c|}
\hline & Mean & SD & $\mathbf{N}$ \\
\hline \multicolumn{4}{|l|}{ Respondents' age group } \\
\hline 20 to 30 years & 39.95 & 6.30 & 56 \\
\hline 31 to 40 years & 40.17 & 7.52 & 134 \\
\hline 41 to 50 years & 42.58 & 6.77 & 228 \\
\hline 51 to 60 years & 42.93 & 7.37 & 200 \\
\hline 61 years or more & 44.28 & 6.44 & 54 \\
\hline \multicolumn{4}{|l|}{ Type of nursing work } \\
\hline \multicolumn{4}{|c|}{ Hospital-based clinical positions } \\
\hline Oncology & 47.12 & 6.48 & 17 \\
\hline Specialty clinic & 43.17 & 5.32 & 48 \\
\hline Surgical & 42.64 & 6.29 & 75 \\
\hline Care of the elderly & 42.41 & 6.03 & 68 \\
\hline Operating theatre & 42.04 & 6.91 & 48 \\
\hline General & 41.63 & 8.20 & 27 \\
\hline Medical & 40.90 & 6.48 & 39 \\
\hline Children's & 40.72 & 6.53 & 25 \\
\hline Cardiology & 40.70 & 6.37 & 23 \\
\hline Psychiatric & 40.57 & 4.75 & 28 \\
\hline Orthopaedic & 39.82 & 6.17 & 11 \\
\hline Clinical nurse specialist & 39.63 & 5.57 & 8 \\
\hline Intensive care units & 39.50 & 6.71 & 44 \\
\hline Accident and emergency & 39.02 & 8.20 & 44 \\
\hline Maternal care & 38.94 & 8.54 & 17 \\
\hline \multicolumn{4}{|c|}{ Non-clinical hospital nursing positions } \\
\hline Practice Nurse & 47.15 & 8.10 & 67 \\
\hline Educator & 45.50 & 5.48 & 12 \\
\hline Occupational health & 45.50 & 6.13 & 4 \\
\hline Prison nurse & 45.00 & 5.43 & 5 \\
\hline District Nurse & 41.74 & 6.66 & 23 \\
\hline Management & 41.00 & 8.29 & 11 \\
\hline Bureau or agency & 40.80 & 5.71 & 10 \\
\hline Public health & 40.06 & 9.77 & 18 \\
\hline
\end{tabular}

\subsection{What Is the Level of Sense of Community among Nurses?}

Females had higher sense of community scores $(n=627, M=42.22, S D=7.21)$ than men $(n=45, M=40.82, S D$ $=6.36)$. Respondents who worked part-time $(\mathrm{n}=425, \mathrm{M}=42.50, \mathrm{SD}=7.21)$ had higher scores than those who worked full-time $(\mathrm{n}=247, \mathrm{M}=41.90, \mathrm{SD}=7.12)$. However, a series of $t$-tests found that none of these differences was significant. Table 2 shows NSCI scores for the seven largest groups of hospital nurses $(n>44)$ in descending order were specialty clinic $(\mathrm{M}=43.17, \mathrm{SD}=5.32)$, surgical $(\mathrm{M}=42.64, \mathrm{SD}=6.29)$, care of the elderly $(\mathrm{M}=42.41$, $\mathrm{SD}=6.03)$, operating theatre $(\mathrm{M}=42.04, \mathrm{SD}=6.96)$, intensive care units $(\mathrm{M}=39.50, \mathrm{SD}=6.71)$ and accident and emergency nurses $(\mathrm{M}=39.02, \mathrm{SD}=8.20)$. However, a series of $t$-tests found that there were no differences 
between the highest scoring group and the other six groups. Using a simple tertile classification of scores where low $=12$ to 28, moderate $=28$ to 44 , and high $=44$ to 60: the mean NSCI score range that of 40.06 to 47.15 indicates that nurses have a moderately high level of sense of community. The highest five scores $(>45)$ are shaded light grey in Table 2. It also appears the level of sense of community gradually increases with age. Respondents in the youngest (20 to 30) age group had the lowest scores $(\mathrm{M}=39.95, \mathrm{SD}=6.30)$. The difference $(t=-3.5, p<0.001)$ between them and the highest scoring group (61 and over) $(\mathrm{M}=44.28, \mathrm{SD}=6.44)$ was confirmed by using a Bonferroni adjustment for the number of comparisons at the $p<0.05$ level.

\section{Discussion}

These data clearly indicate that nurses feel that that are community members. Results support McMillan and Chavis' (1986) sense of community construct among nurses and demonstrate that three elements could be reliably measured. Key findings relate to the high membership and low influence subscale scores; the youngest nurses having the lowest level, and those working in speciality areas such as oncology and practice nursing (i.e., small, close-knit workplaces), the highest level of sense of community.

\subsection{High Membership Subscale Score}

Scores for the membership subscale were the highest. Membership encapsulates the feeling of personal relatedness and has five attributes. Boundaries are formally fixed, with explicit markers of membership (being a registered nurse), joining (graduating, new-graduate and preceptor training) and leaving (parties, farewell and retirement functions) rituals. Emotional safety is provided by membership boundaries and develops as nurses spend time together (often working in close physical contact in a hospital ward or work unit). A sense of belonging and identification involves the feeling, belief, and expectation that one fits in the group and has a place there, a feeling of acceptance by the group and a willingness to sacrifice for the group (such as when nurses are asked help others complete tasks or to work extra shifts). Personal investment is an important contributor to a person's feeling of group membership and to his or her community. Common symbol systems, such as wearing a similar nursing uniform, serve several important functions in creating and maintaining a sense of community and in maintaining group boundaries. Given the strong relationships between these five attributes, attributes, it is easy to see why nurses' scores on the membership subscale were high.

\subsection{Low Influence Subscale Score}

The lowest scores were for influence. Theoretically, influence means that individual group members feel important to the group and consider the group to be important to them. According to McMillan and Chavis (1986), members are more attracted to a community in which they feel they are influential. Given this, the low scores on the influence subscale indicate that the nursing community may be an unattractive proposition and could contribute to the problem of recruitment and retention of nurses. Also, in a strong community, influence operates bi-directionally: members of a group are able to influence their community, and the community exerts control over the behaviour of its members. Low scores are indicative that influence might only operate in one direction: top down, which is not surprising given that the majority of nurses worked in public hospitals and public sector organisations which are hierarchical or bureaucratic organisations designed to efficiently and effectively control employees' work. These findings suggest that nurses felt they had little influence in the hospital and organisations in which they worked.

\subsection{Youngest Nurses}

The lowest level of sense of community was found among the youngest nurses. This is not surprising given that new graduates, who are typically the youngest, may take time to settle into their registered nurses roles. A study by the Professional Nursing Staff Organisation (2007) found a low sense of community among Generation Y nurses (also called Millennials, Generation Next, Nexters) who were described as "a self-reliant, family-orientated, brand-conscious, consumerist, mobile and optimistic group" and "as hardworking, dedicated to their patients, highly connected to their friends and families rather than to their job or a lifelong career" (Professional Nursing Staff Organisation, 2007, p. 1). For young nurses, these characteristics combined with increasing internet connectivity and participation and involvement in virtual and social communities may take precedence over 'real' and personal workplace relationships thereby diminishing the value of belonging to or interacting with an ageing nursing community.

\subsection{Workplace}

Sense of community, as its name implies, derives from the proposal that the benefits ascribed to community come from an internal sense of community, irrespective of any externally observable characteristics of the group in question. So does workplace matter? Even though early membership boundaries are established by a physical 
place or location, such as a nursing classroom, longer term, it does not require that individual members remain in a particular location or setting to retain a sense of belonging to a vocational community of nurses. Thus, the membership element of a sense of community is an enduring and transportable characteristic that makes it easy for nurses to move physically in and out of different clinical or allied practice areas and within geographically different places of nursing practice.

These data however, show that workplace does matter as those nurses based in oncology, specialty areas, education, occupational health and prisons had the highest levels of sense of community. The finding that smaller work groups have a higher sense of community due to increased interactions, and an increased interdependence among members is supported by others e.g., Burroughs \& Eby (1998). Such workplaces are typically smaller, more supportive and provide greater opportunity for daily engagement and direct interpersonal relationships with co-workers. Furthermore, working hours may be more regular, not involve weekend or night shifts and job roles may require postgraduate training and be more challenging, highly technical and prestigious.

\section{Recommendations}

Results of this explorative study demonstrate that sense of community has both physical, i.e. related to place of work and relational, i.e., social/psychological dimensions that work together to provide a sense of membership and belonging to a nursing community. To nurture the development of a sense of community among neophyte nurses it is recommended that nursing education curriculum includes regular communication with students, providing feedback opportunities, and uses strategies such as group work to build opportunities for involvement and engagement with peers. Small group and project-based learning opportunities also connect learners with their community stakeholders, improving nurse's visibility and engagement with community stakeholders. Academic staff should role model collegial and professional relationships that enhance students' inclusion, empowerment and safety (Foli et al., 2013). To build a strong community, all staff must feel like valued, including interdisciplinary team members. Smaller sized workplaces or units are more conducive to fostering the development of sense of community. Nursing leaders should emphasise building community, camaraderie and a sense of teamwork as engaged nurses are more likely to believe in their co-workers and help them in stressful and challenging times. Every staff member should feel a unified commitment to delivering patient-centred care and this starts with a sense of belonging and ownership (Sherman, 2013).

To be more influential, nurses need more input into the more strategic hospital issues, a nursing representative should be chosen from each ward, unit or department to attend management meetings in which pertinent hospital mattes are discussed (Buck, 2017; Seckman, 2014). This representative would be responsible for speaking on behalf of their nursing colleagues at meetings. This simple yet very effective, communication strategy ensures that nurses are informed about current hospital issues and enhance a nurse's sense of belonging to his or her organisational community. Nurses in their early careers need to be placed in supportive sites, and smaller units may be more suitable to developing sense of community. Where appropriate and operationally feasible, primary level organisational interventions such as clarifying job roles through job descriptions and regular performance appraisals are important. Secondary level, protective strategies such as enhancing social support networks, particularly amongst younger workers, both informally but also via line managers will also help to develop a sense of community (Buck, 2017).

Finally, we need innovative programmes to connect the learning and skills of our multi generational workforce to the learning and professional development of younger workers. This includes preceptor and new-graduate mentoring programmes to provide the kinds of formal organisational support that is necessary to maintain and foster social relationships. In-service education and training should emphasise ways to effectively manage stress and develop interpersonal relationships. Postgraduate education courses should include topics such as leadership, developing emotional intelligence and strategies for enhancing teamwork.

\section{Conclusion}

Knowing how a sense of community operates among nurses is essential to the nursing profession's leaders and educators. Establishing communal workplace relationships with colleagues is closely tied to improved physical well-being, job satisfaction and retention, especially among new graduates. Low levels of sense of community among the youngest nurses and high levels among those working in specialty areas deserve attention. Recommendations including preceptor, mentor and development programmes, which facilitate workplace connections, nurture the development of sense of community across the multi-generational workforce.

This study is a significant contribution to the nursing literature because the results demonstrate the presence of a sense of community among nurses and provides evidence that the construct can be reliably measured using the 
NSCI. Accordingly, it is suggested that the NSCI be used to further investigate the theoretical dynamics and nature of this special kind of workplace support.

\section{References}

Benton, D., \& Mitchell, J. (2004). A community of practice. Nursing Standard, 18(52), 16-17. https://doi.org/10.7748/ns.18.52.16.s30

Biester, D. J. (1994). Creating a professional nursing work environment: a story of organizational transformation. Unpublished PhD thesis, University of Colorado Health Sciences Centre.

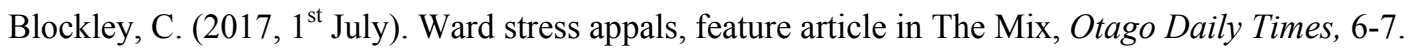

Brodsky, A. (1996). Resilient single mothers in risky neighbourhoods: negative psychological sense of community. $\begin{array}{lllll}\text { Journal of } & \text { Community } & \text { 347-363. }\end{array}$ https://doi.org/10.1002/(SICI)1520-6629(199610)24:4<347::AID-JCOP5>3.0.CO;2-R

Buck, J. (2017) Retention remedy: building a sense of community through appreciative enquiry, Nursing Management, 48(4), 9-12. https://doi.org/10.1097/01.NUMA.0000514065.22949.2a

Burroughs, S. M., \& Eby, L. T. (1998). Psychological sense of community at work: a measurement system and explanatory framework. Journal of Community Psychology, 26(6), 509-532. https://doi.org/10.1002/(SICI)1520-6629(199811)26:6<509::AID-JCOP1>3.0.CO;2-P

Chavis, D. M. (1986). Sense of Community Index. 12522 Hialeah Way, Gaithersburg, MD: Association for the Study and Development of Community.

Chavis, D. M., \& Wandersman, A. (1990). Sense of community in the urban environment: a catalyst for participation and community development. American Journal of Community Psychology, 18(1), 55-81. https://doi.org/10.1007/BF00922689

Chavis, D. M., Hogge, J. H., McMillan, D. W., \& Wandersman, A. (1986). Sense of community through Brunswick's lens: a first look. Journal of Community Psychology, 14, 24-40. https://doi.org/10.1002/1520-6629(198601)14:1<24::AID-JCOP2290140104>3.0.CO;2-P

Chipuer, H. M., \& Pretty, G. M. H. (1999). A review of the sense of community index. Journal of Community Psychology, 27, https://doi.org/10.1002/(SICI)1520-6629(199911)27:6<643::AID-JCOP2>3.0.CO;2-B

Cope, P., Cuthbertson, P., \& Stoddart, B. (2000). Situated learning in the practice placement. Journal of Advanced Nursing, 31(4), 850-856. https://doi.org/10.1046/j.1365-2648.2000.01343.x

Davidson, W., \& Cotter, P. (1986). Measurement of the sense of community within the sphere of the city. Hospitality and Community Psychology, 33(6), 487-488.

Ditzel, E. M. (2008). A study of perceived job stress, sense of community and burnout among New Zealand nurses. Unpublished $\mathrm{PhD}$ thesis, University of Otago, Dunedin.

Ditzel, E. M. (2009). Job stress among nurses: the implications for the healthcare profession. International Journal of Healthcare Research, 1(2), 125-135. https://doi.org/10.1504/IJBHR.2009.024225

Foli, K. J., Karagory, P. M., Gibson, G., \& Kirkpatrick, J. M. (2013). Developing a sense of community among nursing students. Nurse Educator, 38(6), 246-251. https://doi.org/10.1097/01.NNE.0000435267.61236.fb

Klein, K., \& D'Aunno, T. A. (1986, October). Psychological sense of community in the workplace. Journal of Community Psychology, 14,365-377. https://doi.org/10.1002/1520-6629(198610)14:4<365::AID-JCOP2290140405>3.0.CO;2-H

Kübler-Ross, E. (1969). On death and dying. New York: The Macmillan Company.

Laughner, T. C. (2004). Psychological sense of community in on-line learning environments. Unpublished Doctor of Philosophy, Andrews University, School of Education.

McMillan, D. W. (1996). Sense of community. Journal of Community Psychology, 24(4), 315-325. https://doi.org/10.1002/(SICI)1520-6629(199610)24:4<315::AID-JCOP2>3.0.CO;2-T

McMillan, D. W., \& Chavis, D. M. (1986). Sense of community: A definition and theory. Journal of Community Psychology,

14 , 6-23. https://doi.org/10.1002/1520-6629(198601)14:1<6::AID-JCOP2290140103>3.0.CO;2-I 
Plas, J., \& Lewis, S. (1996). Environmental factors and sense of community in a planned town. American Journal of Community Psychology, 24, 109-143. https://doi.org/10.1007/BF02511884

Pretty, G. M. H., \& McCarthy, M. E. (1991). Exploring psychological sense of community among women and men of the corporation. Journal of Community Psychology, 19, 351-361. https://doi.org/10.1002/1520-6629(199110)19:4<351::AID-JCOP2290190407>3.0.CO;2-X

Price, R. H. (1985). Work and community. American Journal of Community Psychology, 13(1), 1-12. https://doi.org/10.1007/BF00923256

Professional Nursing Staff Organisation. (2007). April's Magnet Minute. Magnet Minute.

Royal, M., \& Rossi, R. (1996). Individual-level correlates of sense of community: findings from work-place and $\begin{array}{llll}\text { school. Journal of } \quad \text { Community } & \text { Psychology, 24(4), }\end{array}$ https://doi.org/10.1002/(SICI)1520-6629(199610)24:4<395::AID-JCOP8>3.0.CO;2-T

Sarason, S. B. (1974). The psychological sense of community. San Francisco: Josey-Bass.

Seckman, C. A. (2014, October). Perceived sense of community, cognitive engagement, and learning outcomes among undergraduate nursing students enrolled in an internet-based learning course. CIN: Computers, Informatics, Nursing, 482-489. https://doi.org/10.1097/CIN.0000000000000076

Sherman, R. O. (2013). Building a sense of community on nursing units. American Nurse Today, 8(3), 32-33.

Sonn, C., \& Fisher, A. (1996). Psychological sense of community in a politically constructed group. Journal of Community Psychology, 417-431. https://doi.org/10.1002/(SICI)1520-6629(199610)24:4<417::AID-JCOP9>3.0.CO;2-Q

Spann, M. G. (2000). A critical analysis of the relationship between ways of knowing and sense of community. Unpublished $\mathrm{PhD}$ thesis, North Carolina State University.

Spencer, K. L., Rushton, C. H., Rumizen, M. C., \& McDermott, R. (2003). Sustaining change with communities of practice. KM Review, 6(1), 24-27.

Thuesen, V. L. (2002). Social support, sense of community and self-perceived health. Unpublished MSN thesis, Conzaga University.

Wright, S. P. (2004). Exploring psychological sense of community in living-learning programs and in the university as a whole. Unpublished $\mathrm{PhD}$ thesis, University of Maryland.

\section{Notes}

Note 1. Internal reliabilities of subscales have been reported as follows: membership 0.58 and 0.72 ; influence, 0.37 and 0.38 ; integration and fulfilment of needs, 0.46 and 0.51 ; shared emotional connection, 0.49 and 0.38 (Wright, 2004; Chipuer \& Pretty, 1999, respectively).

Note 2. This has been shown to have an internal reliability coefficient of 0.80 (Perkins et al., 1990), 0.69 (Pretty \& McCarthy, 1991), 0.68 (Wright, 2004), and 0.66 (Chipuer \& Pretty, 1999).\#

\section{Copyrights}

Copyright for this article is retained by the author(s), with first publication rights granted to the journal.

This is an open-access article distributed under the terms and conditions of the Creative Commons Attribution license (http://creativecommons.org/licenses/by/4.0/). 